\title{
Comparison of anthropometric profile and handgrip strength between inter-university volleyball players and a reference group
}

\author{
Archana Khanna ${ }^{1}$, Shyamal Koley ${ }^{2}$ \\ ${ }^{1}$ Department of Physiotherapy, School of Allied Health Sciences, Sharda University, India; ${ }^{2}$ Department of Physiotherapy, \\ Guru Nanak Dev University, Punjab, India
}

\section{Summary}

Study aim: In a volleyball game, multiple elements can influence competitive success, e.g. height, arm span and other anthropometric variables. The present cross-sectional study was undertaken to find out whether any differences exist between Indian inter-university male and female volleyball players as well as between players and a reference group in terms of anthropometry and handgrip strength.

Materials and methods: The present cross-sectional research was conducted on 114 randomly selected Indian inter-university male $(\mathrm{n}=50)$ and female $(\mathrm{n}=64)$ volleyball players aged $18-25$ years. An equal number of reference group individuals who did not participate in any exercise or training programme were also taken. Height, body weight, body mass index (BMI) $\left(\mathrm{kg} / \mathrm{m}^{2}\right)$, hand length, hand breadth, second digit length, fourth digit length, second and fourth digit ratio (2D/4D ratio), upper arm length, forearm length, total arm length, upper arm circumference, hip circumference; humerus and femur biepicondylar diameters, handgrip strength (dominant/non-dominant), arm muscle area, arm area, arm fat area, arm fat index, \% body fat, and \% lean body mass were measured with equipment including an anthropometer, sliding caliper, handgrip dynamometer and skinfold caliper using standard techniques. The data were analysed using SPSS version 17.0. Student's t-test was applied for the comparison of data between players and the reference group. Differences between the groups were analysed using the oneway ANOVA test. Bonferroni post hoc test was applied after application of the ANOVA test. Effect size was also calculated. Statistical significance $(\mathrm{p}<0.05)$ was indicated using a $5 \%$ level of probability.

Results: Male volleyball players had higher mean values in height, body weight, hand length, hand breadth, second and fourth digit length, dominant and non-dominant handgrip strength, humerus and femur biepicondylar diameter, upper arm length, forearm length and total arm length, arm muscle area, arm area and percent lean body mass than the reference group. Similar findings were observed between female players and the reference group also. Statistically significant differences $(p<0.05-0.001)$ were also observed between male and female players except BMI, 2D/4D ratio, and arm fat area. These findings were supported by the effect size $(\eta)$ calculations.

Conclusion: Volleyball players had better height, weight, hand and arm anthropometrics, handgrip strength and \% lean body mass as compared to the reference group. Significant differences were found in anthropometry and handgrip strength between players and reference group individuals, suggesting that these findings could be very useful for player selection and talent identification in sports.

\section{Key words: Handgrip strength - Anthropometry - Percentage body fat - Volleyball players}

\section{Introduction}

For participation in a particular sport, athletes are expected to show certain functional and structural characteristics [53]. A player's success is determined by a number of anthropometric measurements and morphological characteristics, due to which anthropometric profile and body composition of athletes has remained an area of interest for many years $[27,62]$. A correlation has been found between body structure, physical characteristics and sport capabilities using anthropometric measurements. In all the games, height, weight, and other anthropometric variables play a vital role in the player's performance. Physical structure, including the height and segmental length of individual body parts, especially the arm length, is of considerable advantage in selected events in athletics and in certain games. Profiling provides a valuable means to 
identify talent, strength and weakness as well as to assign player position [60]. It helps to study the physique of the athletic as well as non-athletic population and acts as a non-invasive and inexpensive method to collect a vast amount of data $[35,36]$. Although many studies have shown that specific anthropometric characteristics are significantly associated with success in sports [35], different sports require differing body types to achieve maximum performance. According to Massuca and Fragoso [38], body mass can influence an athlete's speed, endurance and power, whereas body composition can affect strength and agility. Hence, it is important to perform anthropometric profiling of the players. Anthropometric comparison of athletes with non-athletic population is important as various studies on physical characteristics of the human body indicate that athletes who are successful in a specific sport differ in somatic characteristics from the general population [20]. Physical characteristics have tremendous influence on the performance level of sportsmen besides personal skill and mental ability. Studies have been conducted on sportsmen regarding their morphological evaluation along with their performance-related morphological issues [10]. These studies revealed that height plays a significant role in contributing to success in some sports since it affects the leverage between muscle volume and bones towards greater speed of movement and power, depending on overall build, fitness and individual ability.

A distinct combination of longitudinal dimensions, such as stature, arm span, leg length, flexibility, muscular strength, muscular power, and inter-limb coordination, is necessary for successful performance [5]. Strength is a fundamental quality necessary in achieving optimal physical function and is defined as the ability to produce more force $[51,54]$. Strong relationships between isometric strength and performance (e.g., jumping and throwing ability) have been reported in various athletic populations $[31,39,40,55,56]$. In many sports, apart from anthropometric measurements, a number of strength and power tests have been used to assess the athletic performance. The force production can be measured by isotonic, isometric or isokinetic methods. The isotonic methods involve lifting a particular weight through a fixed number of repetitions such as 1RM testing or using prediction equations [38]. Isokinetic measurements involve the use of isokinetic devices. The isometric testing is done by a maximal voluntary contraction performed at a specific angle against an unyielding resistance in series with a strain gauge, cable tensiometer, force platform or similar device whose transducer measures the applied force [57]. Isometric assessment of muscle function has been used in exercise science where both maximal force and rate of force development are recorded [63]. These tests have been found to be highly reliable in both single and multijoint test protocols $[43,63]$.
Isometric tests are easy to perform as they require only a single maximal contraction and relatively simple equipment. Hence, the estimation of handgrip strength is of immense importance in sports such as volleyball, tennis, football, basketball and handball as they require a sufficient degree of grip strength. One's grip strength plays a key role in injury prevention and overall strength development $[9,12,18,58]$. Also, handgrip strength is widely used as an indicator of muscle strength in fitness testing $[7,11]$ as well as an indicator for overall muscle strength $[26,28,64]$. Several studies have shown a high correlation of body composition and anthropometric characteristics with technical and tactical demands in volleyball and basketball players $[6,23,25]$. However, limited data are available with respect to the Indian context. Hence, the present study was undertaken to compare the anthropometric profile as well as handgrip strength in inter-university volleyball players and a reference group which would help in their talent identification and performance enhancement.

\section{Materials and methods}

\section{Study Design: Cross-Sectional}

Participants: 114 randomly selected Indian interuniversity male $(n=50)$ and female $(n=64)$ volleyball players in the age group of 18-25 years (mean age of male players: 20.86 years \pm 1.178 ; female players: $20.87 \pm 1.105$ ) were selected from Punjabi University Patiala, Punjab University Chandigarh, Guru Nanak Dev University Amritsar and Kurukshetra University, Kurukshetra. Male and female players had more than one year of playing experience (mean: 1.61, 1.63 years respectively). An equal number of reference group individuals without any athletic background and not involved in any type of exercise or training were also selected for comparison (mean age male reference group: $20.98 \pm 1.220$, female reference group: $20.87 \pm 1.147)$.

Inclusion Criteria: Subjects with the following inclusion criteria were selected for the study:

1. Both male and female inter-university volleyball players in the age group of 18-25 years.

2. Playing experience of 1 or more years.

3. Apparently healthy players not suffering from any medical or musculoskeletal conditions.

Written consent was obtained from the participants. Data were collected 48 hours after the last training session/match, under natural environmental conditions in the morning (between 9 am and $1 \mathrm{pm}$ ) during the months of March-May when the average temperature and humidity were $70^{\circ} \mathrm{F}$ and $71 \%$ respectively. The study was approved by the institutional ethics committee.

A number of variables, viz. height, weight, body mass index, hand length, hand breadth, second digit length, 
fourth digit length, second to fourth digit ratio (2D/4D), upper arm length, forearm length, total arm length, upper arm circumference, hip circumference, humerus and femur biepicondylar diameters, dominant handgrip strength (DHG), non-dominant handgrip strength (NDHG), arm muscle area, arm area, arm fat area, arm fat index, \% body fat, and \% lean body mass, were measured following standard technique [33].

Procedures: A stadiometer (Holtain Ltd., Crymych, Dyfed, UK) was used to record the height to the nearest $0.1 \mathrm{~cm}$ and weight was measured by digital standing scales (Model DS-410, Seiko, Tokyo, Japan) to the nearest $0.1 \mathrm{~kg}$. Upper arm length was measured from the acromion to the radiale using an anthropometer. To measure upper arm length, the subject stood erect on a horizontal surface stretching the body as much as possible with arms hanging by the side. The fixed cross bar of the anthropometer was allowed to touch the acromion and the moving cross bar was allowed to touch the radiale lightly. Results were recorded in $\mathrm{cm}$. Forearm length was measured in centimetres between the radiale and stylion using an anthropometer. Total arm length was measured between the acromion and the dactylion by the anthropometer in centimetres. Hand length, hand breadth, second and fourth digit lengths as well as humerus and femur biepicondylar diameter were measured in centimetres using a sliding caliper. Upper arm and hip circumference were measured using a steel tape in centimetres. Percent body fat ( $\%$ BF) was assessed using skinfold measurements taken from four sites, i.e. biceps, triceps, subscapular and suprailiac, using a Harpenden skinfold caliper (Holtain Ltd, Crosswell, Crymych, UK) to the nearest $0.2 \mathrm{~mm}$ and using the Durnin and Womersley skinfold equation [14]. The readings were reliable (ICC value: 0.892 ) as an expert with experience of four years took these readings from all individuals after performing three trials. Arm area, arm fat area, arm fat index and percentage lean body mass (\% LBM) were calculated using the following formulae:

Arm area $\left(\mathrm{cm}^{2}\right)=\left(\mathrm{G}_{\text {arm }}\right)^{2} / 4 \pi$

Arm fat area $\left(\mathrm{cm}^{2}\right)=$ arm area - arm muscle area

Arm fat index $=$ arm fat area/arm area

$\%$ lean body mass $=100-\%$ body fat

The grip strength of dominant and non-dominant hands was measured using a standard adjustable digital handgrip dynamometer (Takei Scientific Instruments Co., LTD, Japan) in a standing position with the shoulder adducted and neutrally rotated and the elbow at full extension. It was held freely without any support and not touching the subject's trunk. The position of the hand remained constant without a downward direction. Prior to each trial, every individual performed warm-up exercises (five times each) including shaking both hands, and bending, stretching all the fingers (palm up, palm down, ball squeeze, interlace fingers and finger spread with band). Each subject was asked to exert a maximum force on the dynamometer three times from both sides of the hands, maintaining the contraction for 30 seconds during each trial. The maximum value was recorded in kilograms. The handgrip dynamometer was calibrated before each assessment. Handgrip strength was tested when subjects performed 3 minutes of independent warm-up. A thirty-second time interval was maintained between each handgrip strength testing.

\section{Statistical analysis}

Standard descriptive statistics (mean \pm standard deviation) were determined for directly measured variables. Data were analysed using SPSS version 17.0. A normality test was performed using SPSS and the data were found to be well within the normality range. For determining the homogeneity of measures, a goodness of fit test was applied and it was found that the measures were nonhomogeneous. Student's t-test was applied for the comparison of data between players and the reference group. Differences between the groups were analysed using the one-way ANOVA test. The Bonferroni post hoc test was applied after application of the ANOVA test. Statistical significance was indicated using a 5\% level of probability. Effect size was calculated using the formula:

$$
\eta^{2}=\mathrm{SS}_{\text {effect }} / \mathrm{SS}_{\text {total }} \text {, }
$$

where: $\mathrm{SS}_{\text {effect }}$ is the sum of squares between groups. $\mathrm{SS}_{\text {total }}$ is the total sum of squares for all variables, errors and interactions in the ANOVA study.

\section{Results}

Table 1 shows the descriptive statistics, one-way ANOVA and effect size for selected anthropometric characteristics of male and female volleyball players and the reference group. Male players were better in terms of anthropometry and body composition than the reference group. Male players recorded higher mean values than the reference group for height, body weight, hand length, hand breadth, second digit length, fourth digit length, humerus and femur biepicondylar diameters, upper arm length, forearm length, total arm length, arm muscle area and percentage lean body mass (mean difference: 8.69 , $2.04,0.69,0.19,0.41,0.38,0.17,0.04,0.55,2.86,4.47$, 2.54 and 4.5 , respectively).

Female players were also better in terms of anthropometry and body composition than the reference group. They recorded higher mean values than reference group for height, body weight, BMI, hand length, second digit length, fourth digit length, hip circumference, humerus biepicondylar diameter, upper arm length, forearm length, total arm length, and percentage lean body mass (mean difference: $4.83,4.41,0.31,1.05,0.30,0.35,1.4,0.63$, 
Table 1. One-way analysis of variance of selected anthropometric variables in volleyball players and reference group

\begin{tabular}{|c|c|c|c|c|c|c|c|c|c|c|c|}
\hline \multirow[t]{2}{*}{ Variables } & \multicolumn{2}{|c|}{ Volleyball males } & \multicolumn{2}{|c|}{$\begin{array}{l}\text { Reference group } \\
\text { males }\end{array}$} & \multicolumn{2}{|c|}{$\begin{array}{l}\text { Volleyball } \\
\text { females }\end{array}$} & \multicolumn{2}{|c|}{$\begin{array}{l}\text { Reference group } \\
\text { females }\end{array}$} & \multirow{2}{*}{$\begin{array}{c}\begin{array}{c}\text { Effect } \\
\text { size }\end{array} \\
\eta^{2}\end{array}$} & \multirow[t]{2}{*}{ F } & \multirow[t]{2}{*}{$\mathrm{p}$} \\
\hline & Mean & SD & Mean & SD & Mean & SD & Mean & SD & & & \\
\hline Height & 181.0 & 6.02 & 173.11 & 6.00 & 164.97 & 3.91 & 160.14 & 4.75 & 0.196 & 183.79 & 0.001 \\
\hline Body weight & 69.23 & 6.31 & 67.19 & 7.64 & 58.47 & 5.68 & 54.06 & 5.84 & 0.113 & 35.38 & 0.001 \\
\hline BMI & 20.89 & 2.25 & 22.34 & 3.54 & 21.45 & 1.61 & 21.14 & 3.40 & 0.000 & 2.42 & 0.067 \\
\hline Hand length & 19.67 & 0.70 & 18.98 & 0.76 & 18.12 & 0.78 & 17.07 & 0.73 & 0.002 & 123.64 & 0.001 \\
\hline Hand breadth & 8.72 & 0.43 & 8.53 & 0.48 & 7.26 & 0.38 & 7.28 & 0.35 & 0.001 & 197.98 & 0.001 \\
\hline $2^{\text {nd }}$ Digit length & 7.64 & 0.48 & 7.23 & 0.39 & 7.05 & 0.33 & 6.75 & 0.40 & 0.000 & 46.36 & 0.001 \\
\hline $4^{\text {th }}$ Digit length & 7.85 & 0.47 & 7.47 & 0.38 & 7.23 & 0.44 & 6.88 & 0.43 & 0.000 & 48.25 & 0.001 \\
\hline $2 \mathrm{D} / 4 \mathrm{D}$ & 0.97 & 0.02 & 0.97 & 0.03 & 0.98 & 0.03 & 0.98 & 0.02 & 1.363 & 2.62 & 0.052 \\
\hline UAC & 26.60 & 2.98 & 27.40 & 3.48 & 25.36 & 1.73 & 25.74 & 2.85 & 0.001 & 5.78 & 0.001 \\
\hline $\mathrm{HC}$ & 91.89 & 5.70 & 93.51 & 8.30 & 96.77 & 4.55 & 95.37 & 6.72 & 0.009 & 6.03 & 0.001 \\
\hline HBD & 6.89 & 0.56 & 6.72 & 0.85 & 6.25 & 0.42 & 5.62 & 0.42 & 0.000 & 55.89 & 0.001 \\
\hline FBD & 9.05 & 0.96 & 9.01 & 1.15 & 8.70 & 0.39 & 8.92 & 0.66 & 0.000 & 2.26 & 0.082 \\
\hline UAL & 32.07 & 2.64 & 31.52 & 3.68 & 33.53 & 1.96 & 31.45 & 1.73 & 0.002 & 9.16 & 0.001 \\
\hline Forearm length & 29.85 & 1.88 & 26.99 & 2.28 & 27.03 & 1.56 & 26.01 & 1.56 & 0.005 & 42.62 & 0.001 \\
\hline TAL & 81.96 & 4.16 & 77.49 & 3.92 & 77.55 & 3.44 & 73.27 & 3.03 & 0.027 & 52.51 & 0.001 \\
\hline AMA & 44.14 & 9.34 & 41.60 & 1.05 & 37.65 & 5.15 & 39.27 & 8.96 & 0.017 & 5.87 & 0.001 \\
\hline Arm area & 57.01 & 1.24 & 60.73 & 1.56 & 51.44 & 6.83 & 53.40 & 1.18 & 0.036 & 6.51 & 0.001 \\
\hline Arm fat area & 12.87 & 4.88 & 19.12 & 8.11 & 13.79 & 2.08 & 14.13 & 3.30 & 0.015 & 16.24 & 0.001 \\
\hline Arm fat index & 0.22 & 0.06 & 0.31 & 0.08 & 0.27 & 0.02 & 0.27 & 0.27 & 0.000 & 24.32 & 0.001 \\
\hline$\%$ Body fat & 16.64 & 2.59 & 21.14 & 3.88 & 26.53 & 1.58 & 26.95 & 2.05 & 0.051 & 186.25 & 0.001 \\
\hline$\%$ LBM & 83.36 & 3.13 & 78.86 & 4.21 & 73.47 & 1.92 & 73.05 & 2.26 & 0.051 & 185.20 & 0.001 \\
\hline
\end{tabular}

UAC: upper arm circumference, HC: hip circumference, UAL: upper arm length, TAL: total arm length, AMA: arm muscle area, HBD: humerus biepicondylar diameter FBD: femur biepicondylar diameter.

Table 2. One-way analysis of variance of dominant and non-dominant handgrip strength in volleyball players and reference group

\begin{tabular}{|c|c|c|c|c|c|c|c|c|c|c|c|}
\hline \multirow[t]{2}{*}{ Variables } & \multicolumn{2}{|c|}{ Volleyball males } & \multicolumn{2}{|c|}{$\begin{array}{c}\text { Reference group } \\
\text { males }\end{array}$} & \multicolumn{2}{|c|}{ Volleyball females } & \multicolumn{2}{|c|}{$\begin{array}{l}\text { Reference group } \\
\text { females }\end{array}$} & \multirow{2}{*}{$\begin{array}{c}\text { Effect size } \\
\eta^{2}\end{array}$} & \multirow[t]{2}{*}{$\mathrm{F}$} & \multirow[t]{2}{*}{$\mathrm{p}$} \\
\hline & Mean & $\mathrm{SD}$ & Mean & $\mathrm{SD}$ & Mean & $\mathrm{SD}$ & Mean & $\mathrm{SD}$ & & & \\
\hline DHG & 42.63 & 5.63 & 40.32 & 7.20 & 26.87 & 2.78 & 23.19 & 3.82 & 0.205 & 209.53 & 0.001 \\
\hline NDHG & 43.33 & 5.90 & 38.30 & 7.35 & 23.95 & 2.79 & 20.86 & 3.67 & 0.259 & 256.87 & 0.001 \\
\hline
\end{tabular}

DHG: dominant handgrip strength, NDHG: non-dominant handgrip strength

$2.08,1.02,4.28$, and 0.42 respectively). Statistically significant differences $(\mathrm{p}<0.05-0.001)$ were observed for all variables except BMI, 2D/4D ratio and femur biepicondylar diameter.

Table 2 shows the descriptive statistics, one-way ANOVA and effect size for dominant and non-handgrip strength of male and female volleyball players and the reference group. Male and female players were better in terms of dominant and non-handgrip strength than the reference group with an effect size of 0.205 and 0.259 respectively. Statistically significant differences for handgrip strength were observed $(p<0.001)$ between players and the 
reference group. A mean difference of 2.31 and 5.03 was found between male players and the reference group and 3.82 and 3.67 between female players and the reference group respectively.

Figures 1 and 2 show the comparison of mean and standard deviation values for dominant and non-handgrip strength, between players and the reference group respectively.

\section{Discussion}

In determining the success of an athlete, anthropometric dimensions and morphological characteristics play an important role [27, 49, 62]. Volleyball is a specialised sport with specific anthropometric, physical and performance traits, and selection of such players is based on their skills, performance level, physique and muscular strength $[7,13]$. Studies have also shown that volleyball players possess muscular power, jumping prowess, strength and height in blocking, speed for spiking, endurance and agility among other anthropometric characteristics [13, 23].

The findings of the present study indicate that the anthropometric profile of players is significantly better than that of the reference group. Male players had higher mean values for all variables except BMI, upper arm circumference and $\%$ body fat as compared to the reference group. Upon comparison, both male and female volleyball

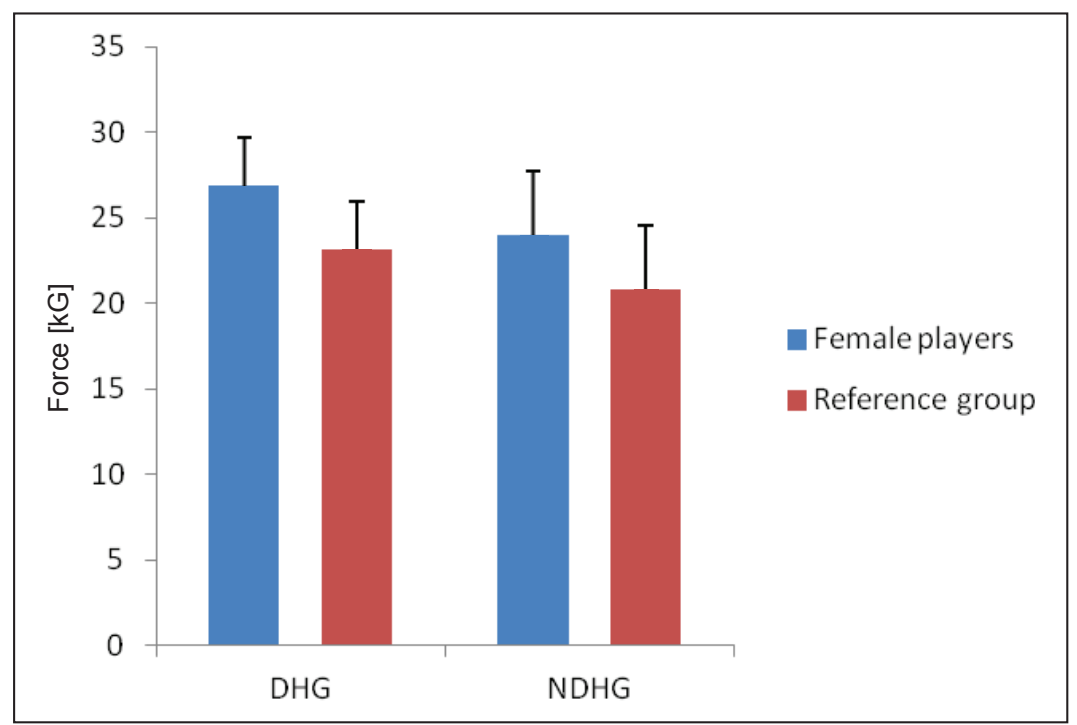

Fig. 1. Comparison of mean values for dominant and non-dominant handgrip strength between female players and reference group

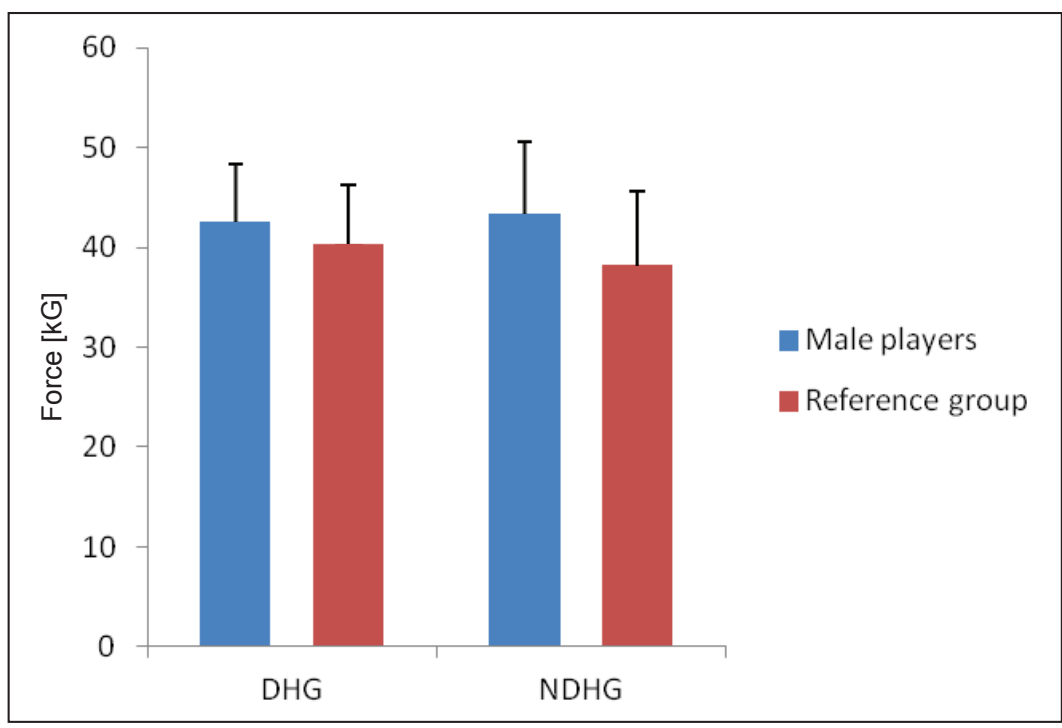

Fig. 2. Comparison of mean values for dominant and non-dominant handgrip between male players and reference group 
players were taller and heavier as compared to the reference group. This is in accordance with the literature reported earlier [21, 22, 24, 37, 48]. Greater values of height in players may be attributed to the fact that elite volleyball players are required to have greater height and strength in the wrist and fingers due to the nature and type of the sport. Also, height is an important factor for selection of players in volleyball. High stature has been recorded as a differential factor between successful and non-successful teams [42]. Therefore, greater height in players provides an advantage in that they can reach over the top of the net as well as performing both offensive and defensive actions over the net $[21,50]$. In a study by Faraji et al. [15], it was found that height and BMI were the most important anthropometric variables in junior female players, suggesting that taller volleyball players would have better handgrip strength. Female players of our study also had higher values for height and handgrip than the reference group. Mean height of male players in the present study was greater than that of players of West Bengal, India $[4,21,22,37,42]$ but less than English $(191.00 \mathrm{~cm}$ \pm 5.0) players [41]. On comparing the present data for height and weight with Bahraini ball game players, Indian players showed higher mean values [1]. However, these values were low when compared to the study done by Hadzic et al. and Pena et al. [24, 47]. Significant greater body weight among volleyball players might be disadvantageous for them in attaining a good jumping height as they have to lift a greater weight [37]. Upon comparison of arm and hand anthropometric variables, players reported better values than the reference group. This is similar to the findings of Koley and Kaur [29].

For volleyball, player selection is based on skills, performance level, physique and muscular strength as specific characteristics and abilities are required according to volleyball specific elements such as height, agility and performance of technical gestures and game movements $[2,13]$. The present study showed that both male and female players had better handgrip strength as compared to their reference counterparts. These findings are similar to those reported earlier $[20,37]$. Due to regular training, greater muscle mass [26], greater height and body weight, players have better handgrip strength. Testosterone levels are one of the leading factors playing a major role in variation of handgrip strength among males. It has been reported that when testosterone level is increased in men, an increase in handgrip strength is found $[46,52$, 61]. In the present study, it was found that both male and female players had better hand dimensions (hand length, hand breadth, second digit length and fourth digit length) as compared to their reference counterparts. This is in line with the findings of Neville and Holder [44], who concluded that the larger the size of the hand, the greater is the handgrip strength.
Studies have shown that various anthropometric and physical characteristics such as height, weight, \% body fat and physical performance parameters positively correlate with higher performance of volleyball players [28]. In the present study, the \% body fat of players was less than that of the reference group following the findings of Tsunawake et al. and Filaire et al. [17, 59]. On comparing the values of \% body fat with high level Spanish volleyball players and elite volleyball players of some Dinaric Alps countries, the male players of the present study had a higher value $[24,47]$. On comparing the results of the present study with the female volleyball players of Japan, America and Turkey, it was found that our female players had lower mean values for height and body weight. However, Japanese players had lower mean values for percent body fat $[3,16,59]$. Higher $\%$ body fat was observed in female players when compared to the study conducted by Nikolaidis et al. [45]. In the literature, body fat values of sporting women are reported between 12-16 percent depending on the type of sport [32]. Malá et al. [34] reported a value of 13.72 percent \pm 2.4 percent of body fat by means of bioimpedance analysis in the Slovak national players who participated in the European Championship of $2009(\mathrm{n}=12$, age $=24.0 \pm 1.1$ years, body height $=$ $179.4 \pm 7.3 \mathrm{~cm}$, body weight $=67.8 \pm 5.9 \mathrm{~kg}$ ). An excessive amount of adipose tissue is considered as unused mass as the athlete has to jump and move repeatedly and overcome the gravitational forces. It results in lowering of performance and an increase of demands on energy during performance of a particular action. The difference between players and the reference group might be due to the effect of regular physical exercise and prolonged training. Low body fat is desirable for high physical performance in all sports. Therefore, significantly low $\%$ body fat in volleyball players as compared to the reference group shows that players have high physical performance.

Both male and female volleyball players had greater upper arm length, forearm length and total arm length than the reference group but lower arm fat area and upper arm circumference. This might be due to less fat on the arm in players [30]. It has been found that physiological and anthropometric characteristics of volleyball players change in response to training and over the course of a season [19]. As far as the effect size is concerned, the variables such as 2D/4D ratio, height and body weight had a considerable effect on handgrip strength in the present study.

The findings of the present study indicate that volleyball players have a better anthropometric profile than the reference group. However, the limitations of the study include the small sample size and the fact that only volleyball players were considered for the study. Also, factors such as socioeconomic status, diet and geographical variations, which could have affected the results, were not taken into consideration. For future studies, the above-mentioned 
limitations should be considered and variables such as playing position, speed and agility can also be included. The present study carries immense importance and practical application, as the findings will contribute to addressing the anthropometric and body composition characteristics of players for coaches, players and managers to understand, formulate and implement effective strategies for coaching programme. Thus, it can be useful in talent identification and improving player selection for tournaments.

\section{Conclusions}

The present study was undertaken to study and compare the anthropometric profile as well as handgrip strength between inter-university volleyball players and a reference group. Players had higher values for height, weight, handgrip strength, hand length and breadth, digit lengths, and upper arm, forearm and total arm lengths than the reference group. \% body fat was found to be low in players whereas handgrip strength was found to be greater as compared to the reference group. These findings indicate that players have a better anthropometric profile than the reference group. Thus, the findings of this study can be utilised for talent identification in sports as well as performance enhancement.

\section{Conflict of interest: Authors state no conflict of interest.}

\section{References}

1. Abdulrahman O.M., Mohammed A.R., Gazi A.M. (1994) Body composition of athletes in Bahrain. Br. J. Sports Med., 28(3): 157-159.

2. Anza R., Denis M., Silva M.F. (2013) Analysis of Physical fitness, anthropometry and prevalence of musculoskeletal symptoms in the youth volleyball category. Rev. Bras. Med. Esporte, 19(1): 62-65.

3. Bamaç B., Colak T., Ozbek A., Yenigün N., Colak S., Bamaç Y. (2003) Volumetric determination of medial epicondyle and lateral epicondyle of humerus in male and female volleyball players. Okajimas Folio Anat. Jpn., 8: 63-70.

4. Bandyopadhyayay A. (2007) Anthropometry and body composition in soccer and volleyball players in West Bengal, India. J. Physiol. Anthropol., 26: 501-505.

5. Barth B., Beck E. (2007) The complete guide to fencing. Oxford: Meyer and Meyer sport (UK) Ltd.

6. Bayios I.A., Bergeles N.K., Apostolidis N.G., Noutsos K.S., Koskolou M.D. (2006) Anthropometric body composition and somatotype differences of Greek elite female basketball, volleyball and handball players. J. Sport. Med. Phys. Fit., 46(2): 271-280.
7. Benetti G., Schneider P., Mezer F. (2005) Sports benefits and the importance of muscular strength trainability in prepubertal volleyball athletes. Revista Brasileira de Cineantropometria e Desempenho Humano, 7: 87-93.

8. Brzycki M. (1993) Strength Testing - Predicting a One Rep Max. from Reps-to-Fatigue. J. Phys. Edu. Rec. Dance, 64(1): 88-90.

9. Budoff J. (2004) The Prevalence of Rotator Cuff Weakness in Patients with Injured Hands. J. Hand Surg., 29(6): 1154-1159.

10. Carter J.E.L. (1984) Physical Structure of Olympic athletes, Part II, Kinanthropometry of Olympic Athletes, Ed Karger, Basel.

11. Cotton O.J., Johnson A. (1968) Use of the T-5 cable tensiometer grip attachment for measuring strength of college men. Res. Q., 41: 454-456.

12. Daisaku T., Nariyuki M., Jun'ya S., Toshihiko O., Masahiko M., Yoshiyuki M. (2005) Relationship between Grip Strength and Surgical Results in Rotator Cuff Tears. Shoulder Joint, 29(3): 559-562.

13. Duncan M.J., Woodfield L., al-Nakeeb Y. (2006) Anthropometric and physiological characteristics of junior elite volleyball players. Br. J. Sports Med., 40: 649-651.

14. Durnin J.V., Womersley J. (1974) Body fat assessed from total body density and its estimation from skinfold thickness: measurements on 481 men and women aged from 16 to 72 years. Br. J. Nutr., 32: 77-97.

15. Faraji E., Sarvari F., Atri A.E. (2014) Predicting grip strength based on anthropometric characteristics in female junior volleyball players. Iranian Journal of Health and Physical Activity, 5(1): 25-28.

16. Ferris D.P., Signorile F., Caruso J.F. (1995) The relationship between physical and physiological variables and volleyball spiking velocity. J. Strength Cond. Res., 9: 32-60.

17. Filaire E., Duche P., Lac G. (1998) Effects of training for two balls on the saliva response of adrenocortical hormones to exercise in elite sportswomen. Eur. J. Appl. Physiol., 77: 452-456.

18. Fry A., Ciroslan D., Fry M., Leroux C., Schilling B., Chiu L. (2006) Anthropometric and Performance Variables Discriminating Elite American Junior Men Weightlifters. J. Strength Cond. Res., 20(4): 861-866.

19. Gabbett T., Georgieff B. (2007) Physiological and anthropometric characteristics of Australian junior national, state and novice volleyball players. J. Strength Cond. Res., 21(3): 902-908.

20. Gaurav V., Singh M., Singh S. (2010) Anthropometric characteristics, somatotyping and body composition of volleyball and basketball players. J. Phys. Educ. Sports Management, 1(3): 28-32.

21. Gaurav V., Singh M., Singh S., Singh A., Sandeep K.R. (2017) A study of hand dimensions and handgrip strength between adolescent basketball and volleyball players. 
American International Journal of Research in Humanities, Arts and Social Sciences, 15-39.

22. Gaurav V., Sandeep K.R., Singh M., Bhanot P. (2015) Anthropometric measurements of volleyball players at different levels of competition. International Journal of Multidisciplinary and Current Research, 3: 999-1002.

23. Gualdi-Russo E.I., Zaccagni I. (2001) Somatotype, role and performance in elite volleyball players. J. Sport. Med. Phys. Fit., 41: 256-262.

24. Hadzic R., Bjelica D., Popovic S. (2012) Comparative study of anthropometric measurement and body composition between elite basketball and volleyball players. Phys. Educ. Sport Health, 1: 103-108.

25. Hooper D.M. (1997) Somatotype in high performance female netball players may influence player position and the incidence of lower limb and back injuries. $\mathrm{Br}$. J. Sports Med., 31(3): 197-199.

26. Kallman D.A., Plato C.C., Tobin J.D. (1990) The role of muscle strength loss in the age-related decline in grip strength: cross-sectional and longitudinal perspectives. $J$. Gerontol., 45: M82-M88.

27. Keogh J. (1999) The use of physical fitness scores and anthropometric data to predict selection in an elite under 18 Australian rules football team. J. Sci. Med. Sport, 2: 125-133.

28. Koley S., Gandhi M., Singh A.P. (2007) An association of Hand Grip Strength with Height, Weight and BMI in Boys and Girls aged 6-25 years of Amritsar, Punjab, India. Internet Journal of Biological Anthropology, (1).

29. Koley S., Kaur S. (2011) Correlations of handgrip strength with selected hand arm anthropometric variables in Indian inter-university female volleyball players. Asian J. Sport. Med., 2(4): 220-226.

30. Koley S., Singh J., Sandhu J.S. (2010) Anthropometric and physiological characteristics on Indian inter university volleyball players, J. Hum. Sport Exerc., 5(3): 389-399.

31. Kraska J.M., Ramsey M.W., Haff G.G., Fethke N., Sands W.A., Stone M.E., Stone M.H. (2009) Relationship between strength characteristics and unweighted and weighted vertical jump height. Int. J. Sport. Physiol. Perform., 4: 461-473.

32. Lohman T.G. (1992) Advances in body composition assessment. Champaign, IL: Human Kinetics.

33. Lohman T.G., Roche A.F., Martorell R. (1988) Anthropometric Standardization Reference Manual Champaign, IL: Human Kinetics Books.

34. Malá L., Malý T., Zahálka F., Bunc V. (2010) The profile and comparison of body composition of elite female volleyball players. Kinesiology, 42(1): 90-97.

35. Malina R.M., Bouchard C., Bar-Or O. (2004) Growth Maturation and Physical activity. 2nd ed. Champaign IL Human Kinetics.

36. Malina R.M., Meleski B.W., Shoup R.F. (1982) Anthropometric, body composition and maturity characteristics of selected school-age athletes. Pediatr. Clin. N. Am., 29: 1305-1323.

37. Mandal N., Maity S., Sahu D. (2015) A study of correlations between dominant handgrip strength with some selected anthropometric and physiological characteristics in inter-college male volleyball players of West Bengal, India. Int. J. Phys. Educ., Sport. Health, 1(5): 17-22.

38. Massuca L., Fragoso I. (2011) Study of Portugese handball players of different playing status. A morphological and biosocial perspective. Biol. Sport, 28(1): 37-44.

39. McGuigan M.R., Winchester J.B. (2008) The relationship between isometric and dynamic strength in college football players. J. Sports Sci. Med., 7: 101-105.

40. McGuigan M.R., Winchester J.B. Erickson T. (2006) The importance of isometric maximum strength in college wrestlers. J. Sports Sci. Med., 5: 108-113.

41. Miltner O., Siebert C., Tschaepe R., Maus U., Kieffer O. (2010) Muscular trunk stability in professional and amateur volleyball players. Zeitschrift für Orthopädie und Unfallchirurgie, 148: 204-209.

42. Morrow J.R., Jackson A.S., Hosler W.W., Kachurik J.K. (1979) The importance of strength, speed, and body size for team success in women's intercollegiate volleyball. Res. Q., 50: 429-437.

43. Murphy A.J., Wilson G.J. (1996) Poor correlations between isometric tests and dynamic performance: relationship to muscle activation. Eur. J. Appl. Physiol. Occup. Physiol., 73: 353-357.

44. Nevill A.M., Bate S., Holder R.L. (2005) Modeling Physiological and anthropometric variables known to vary with body size and other confounding variables. Am. J. Phys. Anthropol., 128(41): 141-153.

45. Nikolaidis P.T., Afonso J. Buśko K. (2015) Differences in anthropometry, somatotype, body composition and physiologica;ll characteristics of female volleyball players by competition level. Sports Sci. Health, 11(1): 29-35.

46. Page S.T., Amory J.K., Bowman F.D., Anawalt B.D., Matsumoto A.M., Bremner W.J., Tenover J.L. (2005) Exogenous testosterone (T) alone or with finasteride increases physical performance, grip strength, and lean body mass in older men with low serum T. J. Clin. Endocrinol. Metab., 90(3): 1502-1510.

47. Pena J., Moreno D.D., Coma J., Cook M., Busca B. (2018) Anthropometric and fitness profile of high level basketball, handball and volleyball players. Revista Andaluza de Medicina del Porte, 11(1): 30-35.

48. Radu L.E., Popovici I.M., Puni A.R. (2015) Comparison of Anthropometric Characteristics Between Athletes and Non-athletes. Procedia Soc. Behav. Sci., 191: 495-499.

49. Rico-Sanz J. (1998) Body composition and nutritional assessments in soccer. Int. J. Sports Nutr., 8: 113-123.

50. Saroha P., Pathak M. (2016) Comparison of selected Psychological and athropometric characteristics between 
successful and unsuccessful volleyball players. J. Sports Phys. Educ., 3(6): 38-42.

51. Siff M. (2000). Biomechanical foundations of strength and power Training. In: Biomechanics in Sport. Ed: Zatsiorsky V. London: Blackwell Scientific Ltd. 103-139.

52. Sih R., Morley J.E., Kaiser F.E., Perry H.M., Patrick P., Ross C. (1997) Testosterone replacement in older hypogonadal men: A twelve month randomized referenceled trial. J. Clin. Endocrinol. Metab., 82: 1661-1667.

53. Singh S., Singh K., Singh M. (2010) Anthropometric measurements, body composition and somatotyping of high Jumpers. Brazilian Journal of Biomotricity, 4: 266-271.

54. Stone M.H. (1993) "Explosive power" Nat. Str. Cond. Assoc. J. 15(4): 7-15.

55. Stone M.H., Sanborn K., O’Bryant H.S., Hartman M., Stone M.E., Proulx C., Ward B., Hruby J. (2003) Maximum strengthpower-performance relationships in collegiate throwers. J. Strength Cond. Res., 17: 739-745.

56. Stone M.H., Sands W.A., Carlock J., Callan S., Dickie D., Daigle K., Cotton J., Smith S.L., Hartman M. (2004) The importance of isometric maximum strength and peak rate-of-force development in sprint cycling. J. Strength Cond. Res., 18: 878-884.

57. Stone M.H., Moir G., Glaister M., Sanders R. (2002) How much Strength is necessary? Phys. Ther. Sport 3: $88-96$.

58. Tietjen-Smith T., Smith S.W., Martin M., Henry R., Weeks S., Bryant A. (2006) Grip strength in relation to overall strength and functional capacity in very old and oldest old females. Phys. Occup. Ther. Geriatr., 63-78.
59. Tsunawake N., Tahra Y., Yukawa K., Katsura T., Harada H. Kikuchi Y. (1995) Characteristics of body shape of female athletes based on factor analysis. Appl. Hum. Sci., 14: 55-61.

60. Vishwanathan J., Nageswara A.S., Baskar S. (2010) Anthropometric assessment of youth national championship basketball players in relation to playing position. $\mathrm{Br} . \mathrm{J}$. Sports Med., 44: i36-i37.

61. Wang C., Swerdloff R.S., Iranmanesh A., Dobs A., Snyder P.J., Cunningham G., Matsumoto A.M., Weber T., Berman N. (2000) Transdernal testosterone gel improves sexual function, mood, muscle strength, and body composition parameters in hypogonadal men. J. Clin. Endocrinol. Metab., 85: 2839-2853.

62. Wilmore J.H., Costill D.L. (1999) Physiology of Sport and Exercise. 2nd ed. Champaign, Human Kinetics.

63. Wilson G.J., Murphy A.J. (1996) The use of Isometric tests of muscular function in athletic assessment. Sports Med. 22(1): 19-37.

64. Wind A.E., Takken T., Helders P.J.M., Engelbert R.H.H. (2010) Is grip strength a predictor for total muscle strength in healthy children, adolescents, and young adults? Eur. J. Pediatr., 69: 281-287.

\section{Received 30.06.2019 \\ Accepted 22.02.2020}

(c) University of Physical Education, Warsaw, Poland 